\title{
Two Body Abrasive Wear of Al-Mg-Si Hybrid Composites: Effect of Load and Sliding Distance
}

\author{
Kaushik NALLAN CHAKRAVARTULA *, Narasimha Rao RAJAMALLA \\ Department of Mechanical Engineering, National Institute of Technology-Warangal, Telangana-506004, India \\ cross $^{\text {ref }}$ http://dx.doi.org/10.5755/j01.ms.22.4.12688
}

Received 14 June 2015; accepted 03 October 2015

\begin{abstract}
The present study investigates on the two body abrasive wear behavior of Al-6082 alloy, Al 6082 alloy-10\% SiC (Al$\mathrm{SiC}$ ) composites and $\mathrm{Al} 6082$ alloy $-5 \% \mathrm{SiC}-5 \% \mathrm{Gr}(\mathrm{Al}-\mathrm{SiC}-\mathrm{Gr})$ hybrid composites. These composites were prepared by stir casting process. The wear tests of these materials were conducted at load of $5-15 \mathrm{~N}$ and sliding distance of $50-$ $75 \mathrm{~m}$ at grit size of $200 \mu \mathrm{m}$. The wear response influenced by these parameters was analyzed and compared with each other. The results show that graphitic composites yielded better wear resistance compared to alloy and single SiC reinforced composite. Worn surfaces of samples were observed by using scanning electron microscope (SEM) and it was revealed that the wear grooves appeared to be narrow and shallow in case of hybrid composites.

Keywords: two body abrasive wear, hybrid composites, wear resistance, worn surface, SEM.
\end{abstract}

\section{INTRODUCTION}

Wear of the critical components like cylinder blocks, cylinder liners, brake drums, drive shafts etc. was one of the serious concerns that affect the overall operational efficiency in automotive applications. In this regard, several experimental investigations have been made in adding individual reinforcements such as $\mathrm{SiC}, \mathrm{Al}_{2} \mathrm{O}_{3}$, graphite etc. to aluminium matrix metal. This lead to improvement in not only mechanical properties but also tribological properties of the materials. The aluminum metal matrix composites (Al-MMCs) have been successfully introduced in automobile, aircraft, space equipment and structural components [1-6]. Automobile companies like Honda, Nissan, Toyota, and General Motors etc. have successfully implemented these AlMMCs in different engine applications by using various particle and fiber type reinforcements [6].

Recent investigation studies show that attention has been given in reinforcing multiple reinforcements i.e. graphite and $\mathrm{SiC}$ to aluminium matrix which produced by different techniques. This was done to know the synergistic effects of hard type and soft type of reinforcements in the sliding wear behaviour on the matrix material. It was proven that wear behavior of Al MMCs with multiple reinforcements was found to be superior compared to alloy and single reinforcement [7-11]. It was reported that the graphite addition was found to be advantageous in tribolayer formation, subsurface deformation and machining of $\mathrm{Al}-\mathrm{SiC}$ composites [9]. It was noted that the studies on sliding wear behavior of these hybrid composites was studied and well understood. It was found that further investigation is required to study the abrasive wear behavior of $\mathrm{Al}-\mathrm{SiC}-\mathrm{Gr}$ hybrid composites. In the present work, two body abrasive wear characteristics were evaluated for $\mathrm{Al}$ hybrid composites with variation of load.

\footnotetext{
* Corresponding author. Tel.: +91-9440857505; fax: +91-0870-246230. E-mail address: kaushiknch1234@gmail.com (K. Nallan Chakravartula)
}

\section{EXPERIMENTAL PROCEDURE}

\subsection{Preparation of composites}

Al 6082 alloy $(\mathrm{Cu}-0.06 \%, \mathrm{Mg}-0.77 \%, \mathrm{Si}-0.95 \%$, $\mathrm{Fe}-0.32 \%, \mathrm{Mn}-0.532 \%, \mathrm{Zn}-0.016 \%, \mathrm{Ti}-0.037 \%$, $\mathrm{Cr}-0.038 \%$ and $\mathrm{Al}-$ balance) was used as matrix material whereas $\mathrm{SiC}$ and graphite particles (size: $20-40 \mu \mathrm{m}$ ) were used as reinforcements. The $\mathrm{Al}-10 \mathrm{wt} . \% \mathrm{SiC}$ and $\mathrm{Al}-$ $5 \mathrm{wt} . \% \mathrm{SiC}-5 \mathrm{wt} \% \mathrm{Gr}$ composites were synthesized by liquid metallurgy route i.e. stir casting technique. $\mathrm{Al} 6082$ alloy ingots were melted in graphite crucible using a coal fired furnace. $\mathrm{SiC}$ and graphite particles were preheated to $\sim 500{ }^{\circ} \mathrm{C}$ and the particles were added to the molten alloy during stirring action created by mechanical stirrer. The vortex mixing (i.e. during addition of particles) was carried for 10 minutes at 400 RPM. Later the molten slurry was poured into stainless steel mold of $170 \mathrm{~mm}$ length and $\varnothing 40 \mathrm{~mm}$. After solidification, the flat pin samples of length $27 \mathrm{~mm}$ length and $\varnothing 8 \mathrm{~mm}$ were prepared by using wire cut electric discharge machining process.

\subsection{Wear testing of composites}

The two body abrasion tests were done on a pin-ondisc machine (Magnum make, model: TE-165-SPOD, Bangalore). The tests were done at load $(5 \mathrm{~N}, 10 \mathrm{~N}$ and $15 \mathrm{~N})$ and sliding distance $(50 \mathrm{~m}, 63 \mathrm{~m}$ and $75 \mathrm{~m})$ on $200 \mu \mathrm{m}$ grit size silicon carbide emery paper. The time duration adopted for each experiment was 60 seconds. The morphology of emery paper before testing was shown in Fig. 1. The emery paper was cut to size and bonded on a wheel of $50 \mathrm{~mm}$ diameter, $12 \mathrm{~mm}$ thickness to serve as an abrasive medium. The specimens were cleaned prior to the wear tests using acetone and weight loss was measured. After testing, the worn surface analysis of the pin materials was done by using scanning electron microscopy (SEM). 


\section{RESULTS AND DISCUSSION}

\subsection{Two body abrasive wear characteristics}

The wear rate calculated from the weight loss results were depicted in the form of bar charts shown in Fig. 2. The effect of load and sliding distance on the abrasive wear at constant $200 \mu \mathrm{m}$ grit size silicon carbide emery paper was studied in this present work. It was observed that from the Fig. 2 a at $50 \mathrm{~m}$ as load increased from $5 \mathrm{~N}$ to $15 \mathrm{~N}$, the wear rate of alloy increased from 0.737 to $1.4615 \mathrm{~mm}^{3} / \mathrm{m}$ for alloy. For Al-SiC composites and AlSiC-Gr composites, the wear rate increased from 0.5362 to $1.2789 \mathrm{~mm}^{3} / \mathrm{m}$ and 0.3964 to $1.1774 \mathrm{~mm}^{3} / \mathrm{m}$ respectively. The similar trends were also observed at $63 \mathrm{~m}$ and $75 \mathrm{~m}$ sliding distances. This is shown in Fig. 2 b and c. At $15 \mathrm{~N}$ load and $75 \mathrm{~m}$ sliding distance, the alloy and composite materials suffered maximum wear in the present set of experiments. The results from Fig. 2 show that as the sliding distance increased from $50 \mathrm{~m}$ to $75 \mathrm{~m}$, the wear rate of alloy, $\mathrm{Al}-\mathrm{SiC}$ and $\mathrm{Al}-\mathrm{SiC}-\mathrm{Gr}$ composites slightly increased from 1.4615 to $1.4996 \mathrm{~mm}^{3} / \mathrm{m}, 1.2789$ to $1.3257 \mathrm{~mm}^{3} / \mathrm{m}$ and 1.1774 to $1.2535 \mathrm{~mm}^{3} / \mathrm{m}$ respectively at $15 \mathrm{~N}$ load. This shows that as load and sliding distance increases, the wear rate increases irrespective of materials. It further indicates that from the results the wear resistance of $\mathrm{Al}-\mathrm{SiC}$ and $\mathrm{Al}-\mathrm{SiC}-\mathrm{Gr}$ was superior compared to alloy material. The improvement of $\mathrm{Al}-\mathrm{SiC}$ and $\mathrm{Al}-\mathrm{SiC}-\mathrm{Gr}$ was $11.6 \%$ and $16.4 \%$ respectively when compared to that of alloy. The order sequence of the wear rate of materials was $\mathrm{W}(\mathrm{Al}$ alloy $)>\mathrm{W}(\mathrm{Al}-\mathrm{SiC})>\mathrm{W}(\mathrm{Al}-\mathrm{SiC}-\mathrm{Gr})$, where $\mathrm{W}$ is wear rate. This shows that positive effect on wear process by adding reinforcements to the alloy material. The similar trends were reported in case of sliding wear of aluminium hybrid composites [7-11].

In the initial abrasive wear process, the hard asperities on the counter surface tend to plough plastically the material on pin surface. As the load increases, the level of penetration of these hard asperities into pin material tend to increase. The level of asperity height dominates the initial wear process and there would be more cutting efficiency. Due to this cutting and ploughing action, the fragmentation, material flow and grooves formation takes place. There would be accumulation of fragments of softer pin in between the valleys of hard asperities on counter surface. As time duration of abrasive action increases the cutting efficiency shall decrease. This could be due to deformation of the abrasive grit particles on the counter surface and the rake angle of individual particle gets disturbed. This deformation could be attributed to brittleness of asperities on counter body.

But in the case of composites, the hard SiC particles present in the $\mathrm{Al}-\mathrm{SiC}$ composites would try to hinder and arrest the material flow process. The interface bond strength between matrix material and $\mathrm{SiC}$ particle decides the abrasive wear process of $\mathrm{Al}-\mathrm{SiC}$ composites. In the initial stages, the material on pin surface gets ploughed as in this case alloy material. This will lead to the protrusion of $\mathrm{SiC}$ reinforcements on pin surface [12]. When these particles encounter with hard asperities on counter surface, the particles tend fracture and break. If the interface bond between the reinforcement particle and matrix material is weak, then the particle gets detached and try to stay in between pin surface and counter body surface. This will lead to abrasive cutting action of that particle which may slide or rotate or roll. If the hard asperities are loosely bound or detach due to shearing action between pin and counter body during wear process, these asperities come into further abrasive action as previously mentioned.

In hybrid composites, the $\mathrm{SiC}$ particles try to reduce the material flow due to plastic deformation. The graphitic layer formed due to presence of graphite particles in the pin material serves as solid lubricant. The graphite released onto the pin surface reduce the friction coefficient. Ted et al. reported that lower than 5 vol \% graphite in the pin material, the lower would be the release of graphite amounts and fracture toughness dominates in this wear process. The solid lubricant effect dominates this fracture toughness only if sufficient graphite amounts are present in pin material [7].

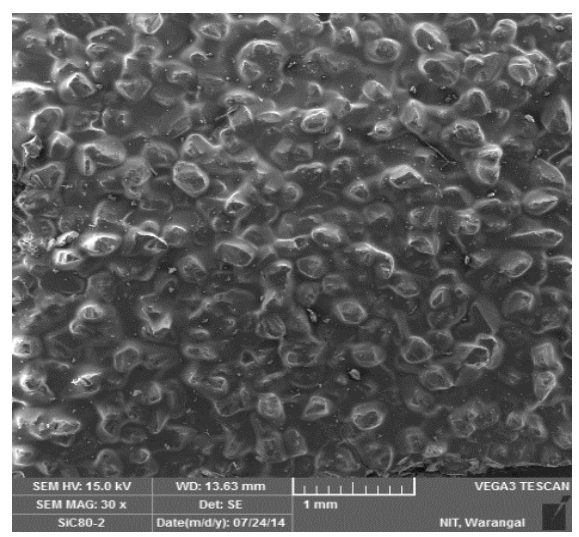

Fig. 1. Topography of $200 \mu \mathrm{m}$ grit size emery paper used in the abrasion tests

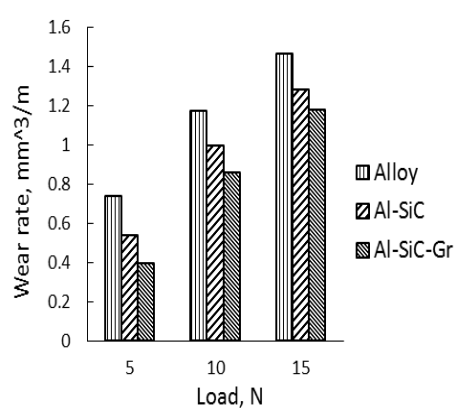

a

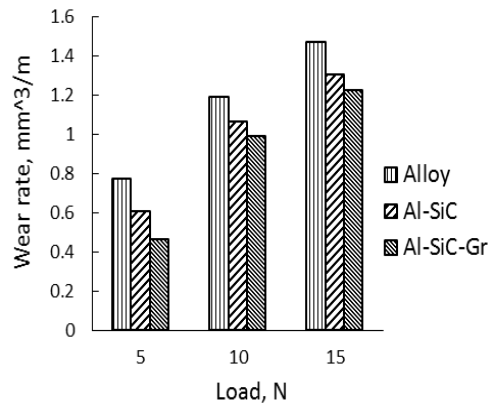

b

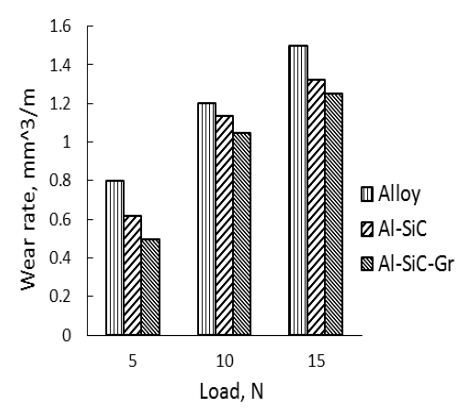

c

Fig. 2. Wear rate Vs Load of alloy and its composites at sliding distance: $a-50 \mathrm{~m} ; \mathrm{b}-63 \mathrm{~m} ; \mathrm{c}-75 \mathrm{~m}$ on $200 \mu \mathrm{m}$ abrasive grit paper 


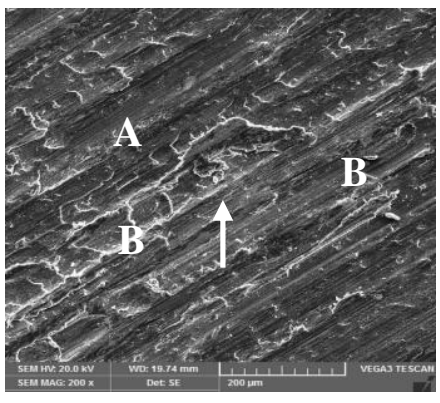

a

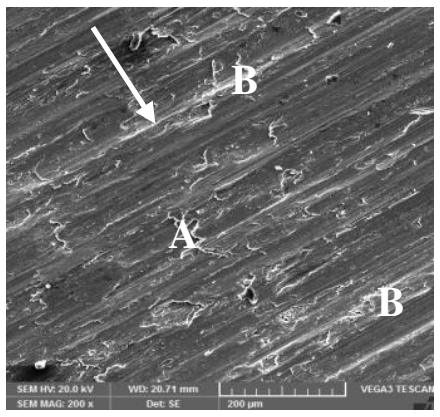

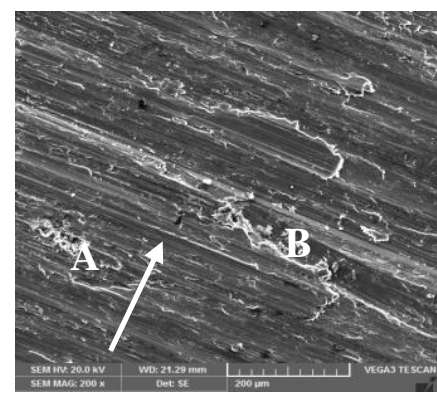

b

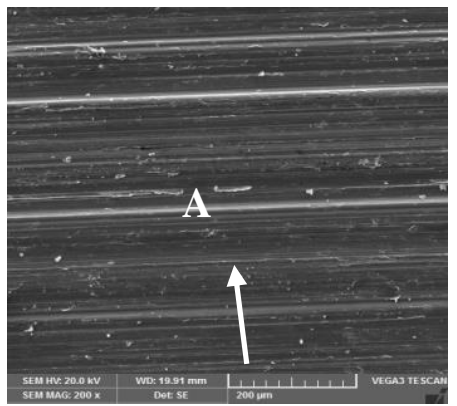

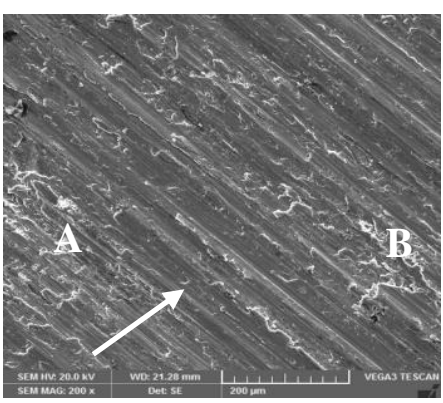

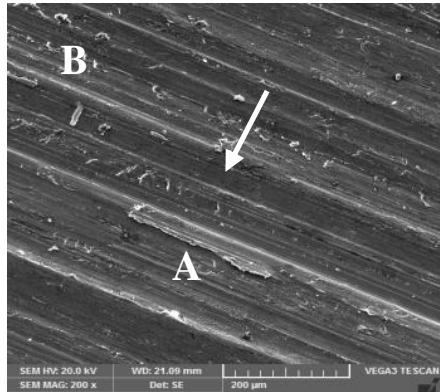

Fig. 3. Worn surface topographies of: $a$-alloy at lower load; b-alloy at higher load; $c-A l-S i C$ composite at lower load; $\mathrm{d}-\mathrm{Al}-\mathrm{SiC}$ composite at higher load; e-Al-SiC-Gr composite at lower load; $\mathrm{f}-\mathrm{Al}-\mathrm{SiC}-\mathrm{Gr}$ composite at higher load

Hence, it was found that the role of lubricant effect of graphite present in hybrid composites lead to further reduction of two body abrasive wear.

\subsection{Examination of worn surfaces}

The worn surfaces of alloy, Al-SiC and Al-SiC-Gr composites were studied to understand and predict the possible material removal mechanism happened in the wear process. The images were captured in secondary electron mode at 200X magnification.

Fig. 3 a, c, e show the abrasive worn surface topographies of alloy, Al-SiC, Al-SiC-Gr tested at lower loads respectively. Fig. $3 \mathrm{~b}$, d and $\mathrm{f}$ show the abrasive worn surface topographies of alloy, Al-SiC, Al-SiC-Gr tested at higher loads respectively. The long continuous grooves (marked with white arrows) and some damaged portions formed during wear process are shown in Fig. $3 \mathrm{a}-\mathrm{f}$.

In the case of alloy, the longitudinal cracks (marked as A), some damaged portions (marked as B) and debris of flaky shaped are formed. These are represented in Fig. 3 a, b. Similar long continuous grooves were observed in Al$\mathrm{SiC}$ composites (Fig. $3 \mathrm{c}$, d) and Al-SiC-Gr composites (Fig. 3 e, f). The damaged portions were found to be minimal in case of composites. It was even lower in hybrid composites due to sacrificial layer formed by graphite. This partial deformation can be observed in the Fig. $3 \mathrm{c}-\mathrm{f}$. This could be due to presence of hard and soft type of reinforcements.

\section{CONCLUSIONS}

Based on the present experimental investigation, the following conclusions were drawn:

1. The composites were prepared using liquid metallurgy route.
2. Two body abrasive wear tests were carried at load 5$15 \mathrm{~N}$ and sliding distance $50-75 \mathrm{~m}$ on $200 \mu \mathrm{m}$ grit size emery paper.

3. As the load increases to $15 \mathrm{~N}$, the improvement of wear rate of $\mathrm{Al}-\mathrm{SiC}$ and $\mathrm{Al}-\mathrm{SiC}-\mathrm{Gr}$ was $11.6 \%$ and $16.4 \%$ respectively when compared to alloy at $75 \mathrm{~m}$ sliding distance. This shows that Al-SiC-Gr composites yielded better abrasive wear resistance properties when compared with single $\mathrm{SiC}$ reinforced composite and alloy materials. The combination of $\mathrm{SiC}$ (hard) and graphite (soft) reinforcements found to beneficial due to formation of graphitic film which acts as a self-lubricant in Al-SiC-Gr composites. This lubricating layer would act as sacrificial layer during cutting and ploughing mechanism involved in abrasive wear process.

4. The worn surfaces analysis of samples was carried out to understand the wear mechanism. The shallower grooves were observed in graphitized composites when compared to alloy and un-graphitized composites. Lesser fragmentation was observed in case hybrid composites compared to Al-SiC material and alloy material. It was evident that the damaged portions of composites found to lower due to restricted plastic flow.

\section{Acknowledgments}

I would like to thank the entire management of NITWarangal who supported directly/indirectly during my research work.

\section{REFERENCES}

1. Rohatgi, P.K. Cast Aluminum Matrix Composites for Automotive Applications Journal of The Minerals, Metals \& Materials Society 43 (4) 1991: pp. 10-15. 
http://dx.doi.org/10.1007/BF03220538

2. Lloyd, D.J. Particle Reinforced Aluminium and Magnesium Matrix Composites International Material Review 39 (1) 1994: pp. 1-23.

3. Nitsham, A.E. New Application for Al Based MMC Light Metal Age 53 1997: pp. 53-54.

4. Rawal, R.S. Metal Matrix Composites for Space Applications Journal of The Minerals, Metals \& Materials Society 53 (4) 2001: pp. 14-17. http://dx.doi.org/10.1007/s11837-001-0139-z

5. Das, S. Development of Aluminium Alloy Composites for Engineering Applications Transactions of Indian Institute of Metals 57 (4) 2004: pp. 325-334.

6. Prasad, S.V., Asthana, R. Aluminium Metal-Matrix Composites for Automotive Applications: Tribology Considerations Tribology Letters 17 (3) 2004: pp. $445-453$. http://dx.doi.org/10.1023/B:TRIL.0000044492.91991.f3

7. Ted Guo, M.L., Tsao, C.Y.A. Tribological Behavior of Self-Lubricating Aluminium-Sic-Graphite Hybrid
Composites Synthesized by The Semi-Solid Powder Densification Method Composites Science and Technology 60 (1) 2000: pp. $65-74$. http://dx.doi.org/10.1016/S0266-3538(99)00106-2

8. Basavarajappa, S., Chandramohan, G. Dry Sliding Wear Behavior of Hybrid Metal Matrix Composites Material Science 11 (3) 2005: pp. 253-257.

9. Suresha, S., Sridhara, B.K. Wear Characteristics of Hybrid Aluminium Matrix Composites Reinforced with Graphite and Silicon Carbide Particulates Composites Science and Technology 70 (11) 2010: pp. 1652-1659.

10. Vamsi Krishna, M., Xavior, A.M. An Investigation on the Mechanical Properties of Hybrid Metal Matrix Composites Procedia Engineering 97 2014: pp. 918-924.

11. Elango, G., Raghunath, B.K. Tribological Behavior of Hybrid (LM25Al-SiC-TiO2) Metal Matrix Composites Procedia Engineering 64 (1) 2015: pp. 671-680.

12. Al-Rubaie, K.S., Yoshimura, H.N., de Mello, J.D.B Two Body Abrasive Wear of Al-SiC Composites Wear 233235 1999: pp. $444-454$. 